\title{
Pedicle screw fixation of thoracolumbar fractures: conventional short segment versus short segment with intermediate screws at the fracture level—a systematic review and meta-analysis
}

\author{
Carolijn Kapoen $^{1}$ (1) $\cdot$ Yang Liu² Frank W. Bloemers $^{1} \cdot$ Jaap Deunk ${ }^{1}$
}

Received: 4 April 2020 / Revised: 4 April 2020 / Accepted: 25 May 2020 / Published online: 11 June 2020

(c) The Author(s) 2020

\begin{abstract}
Objective Posterior short-segment fixation (4-screw construct=4S) is the conventional surgical technique for thoracolumbar fractures. The effect of adding two intermediate pedicle screws at the fractured level $(6$-screw construct $=6 \mathrm{~S})$ is still a matter of debate. This review aims to compare the results between 4 and $6 \mathrm{~S}$ pedicle screw fixation for thoracolumbar fractures. Methods A systematic review and meta-analysis were performed. The databases PubMed, Embase and Google Scholar were searched until January 2020. Inclusion criteria were studies comparing $4 \mathrm{~S}$ and $6 \mathrm{~S}$ techniques in patients with thoracolumbar fractures. Non-comparative studies and studies without full text were excluded. Cochrane risk of bias was assessed, and the GRADE approach was used to present the quality of evidence.

Results Twenty-seven studies, of which 21 randomized controlled trials, with a total of 1890 patients (940 with 4S and 950 with 6S) were included. Meta-analysis showed that the $6 \mathrm{~S}$ technique resulted in significantly lower pain scores, better shortterm and long-term Cobb angles, less loss of correction and less implant failures. However, longer operation time and more blood loss were seen with the $6 \mathrm{~S}$ technique. Length of hospital stay, Oswestry Disability Index scores and infections did not differ significantly between the $6 \mathrm{~S}$ and $4 \mathrm{~S}$ techniques. Quality of the evidence according to GRADE was moderate to low. Conclusion In the treatment of thoracolumbar fractures, adding intermediate screws at the fracture level (6S) results in less post-operative pain, better radiological outcomes and less implant failure at the cost of a longer operation time and higher blood loss.
\end{abstract}

Keywords Thoracolumbar fracture $\cdot$ Spine $\cdot$ Pedicle screw $\cdot$ Fracture level $\cdot$ Intermediate screw

\section{Introduction}

Thoracolumbar fractures are the most common spinal injuries [1]. Although treatment remains controversial in some fracture types, posterior fixation is the most frequently used surgical technique to restore vertebral body height, correct kyphotic deformity, restore spinal stability and indirectly decompress the spinal canal [2]. The conventional surgical technique of posterior fixation is a short-segment 4-screw

Carolijn Kapoen

c.m.kapoen@student.vu.nl

1 Department of Trauma Surgery, VU University Medical Center, Amsterdam UMC, 1081 HV Amsterdam, The Netherlands

2 Department of Clinical Sciences Lund, Orthopedics, Lund University, Faculty of Medicine, 22185 Lund, Sweden construct with pedicle screws one level above and one level below the fractured vertebra. However, several studies showed loss of reduction after short-segment pedicle screw fixation and undesirable rates of implant failure, especially in fractures with loss of anterior support due to comminution [3-7].

For this reason, several modifications of the surgical technique have been proposed to improve outcomes. A biomechanical study in 1994 by Dick et al. first reported the posterior short-segment fixation combined with two additional screws at the fracture level (6 screw construct) [8]. Since this method was first introduced, the technique has evolved. A series of biomechanical studies showed that the addition of screws at the fracture level could significantly increase spinal stability, provide stronger fixation and decrease the stress in the pedicle screws in the nonfractured vertebra [9-13]. However, inconsistent effects of additional screws at fracture level were reported in several 
small clinical trials, limiting the evidence for this surgical technique [14-16]. Consequently, the surgical technique with intermediate screws is still not widely used.

Therefore, this systematic review and meta-analysis were performed on all available studies and data to compare the outcomes of conventional short-segment posterior pedicle screw fixation (4-screw construct $=4 \mathrm{~S}$ ) to shortsegment posterior pedicle screw fixation combined with intermediate screws at the fracture level (6-screw construct $=6 \mathrm{~S}$ ) in patients with thoracolumbar fractures.

\section{Methods}

This systematic review and meta-analysis were performed according to the guidelines of the preferred reporting items for systematic reviews and meta-analyses statement (PRISMA) [17].

\section{Literature search strategy}

The databases PubMed, Embase, Cochrane and Google Scholar were searched for relevant articles to answer the stated research question. The final literature search was conducted on January 15, 2020. Additional relevant studies were also manually searched. The following key search terms were used: "thoracolumbar fracture", "intermediate screw", "additional screw", "fracture level" and "fractured vertebra". The complete search consisted of the mentioned key terms and its variants.

\section{Selection criteria and selection of articles}

Studies were included if the following inclusion criteria were met: (1) patients with thoracolumbar fractures; (2) patients undergoing posterior short-segment pedicle screw fixation; and (3) studies comparing $4 \mathrm{~S}$ and $6 \mathrm{~S}$ techniques. Articles were excluded based on the following criteria: (1) full text not available; (2) incorrect publication type (case reports/systematic reviews); and (3) non-comparative study design. There was no language restriction.

Titles and abstracts identified by the literature search were screened for relevancy. Irrelevant abstracts were excluded. The full text of the remaining titles and abstracts was retrieved and was assessed for eligibility. After fulltext assessment, relevant articles were included in this systematic review and meta-analysis. In addition, the reference list of each included article was screened for new and/or missing studies. If the additionally identified articles met the inclusion criteria, they were included.

\section{Data extraction}

The following variables of interest were extracted from the included studies: demographics (name of first author, publication date, study design, sample size, mean age, gender, mean follow-up period), type and level of fracture, operation techniques (open or percutaneous surgical technique, fusion status) and the outcome parameters. The outcome parameters studied in this review included operation time, hospital length of stay (LOS), intraoperative blood loss, visual analog scale (VAS), Oswestry Disability Index (ODI), short-term and long-term post-operative Cobb angle, post-operative anterior vertebral body height (AVBH), correction loss of Cobb angle, correction loss of AVBH, rate of implant failure and post-operative infection.

\section{Definitions of outcome parameters}

The VAS is a measuring instrument to quantify pain severity, with higher score indicating greater pain intensity (scale $0-10)$. The ODI is a questionnaire on ten domains to quantify disability due to low back pain $(100 \%=$ complete disability and $0 \%=$ no disability). The Cobb angle is defined as the angle between the superior end plate of the upper vertebra and the inferior end plate of the lower vertebra. The AVBH is defined as the anterior height of the fractured vertebra.

\section{Quality of the evidence assessment}

The Cochrane risk of bias tool was used to determine the quality of the included RCTs. The criteria set up by the Cochrane handbook for systematic reviews of interventions [18] were used. To assess the quality of the evidence for each outcome, the Grading of Recommendations Assessment, Development and Evaluation (GRADE) was used (GRADEpro GDT, McMaster University, 2015). Two reviewers independently assessed the quality of each included study and the quality of the evidence. Any discrepancies were resolved through a consensus discussion.

\section{Statistical analysis}

Statistical analysis for the meta-analysis was performed using Review Manager 5.3 [19]. The odds ratio (OR) and the standardized mean difference (SMD) were calculated for the dichotomous and continuous outcomes, respectively. Both the OR and MD were reported with the 95\% confidence intervals (CIs). A $P$ value lower than 0.05 was considered statistically significant. For the continuous outcome measures, a random effect model was used, 
because it cannot be assumed that all differences between effect sizes observed in our included studies are only due to sampling error [20]. For the dichotomous outcomes, the fixed effect model was used. A subgroup analysis was performed to determine difference in results for the open and percutaneous surgical technique.

\section{Results}

\section{Literature search}

The primary literature search showed 644 potential studies from the searched databases, and 20 additional records were identified through other sources. 620 abstracts were screened, and 77 full-text articles were evaluated after removal of irrelevant abstracts. After applying the exclusion criteria, 27 full-text articles were found to be eligible for inclusion in this systematic review and meta-analysis. See Fig. 1.

\section{Study characteristics}

The 27 selected studies included a total of 1890 patients, with 940 patients in the 4-screw construct group and 950 patients in the 6-screw construct group. Twenty studies were randomized controlled trials and 7 retrospective cohort studies. In three studies a percutaneous surgical technique was used and in 25 studies an open surgical technique.

\section{Quality of the evidence assessment}

A risk of bias summary for the included RCTs is presented in Fig. 2. Quality rating of the evidence of each outcome according to GRADE is presented in Table 1 .

\section{Outcome parameters}

\section{Operation time}

Fifteen studies [1, 14, 15, 21-32] provide information on the operation duration (928 patients). Combining these results shows that the placement of intermediate screws prolongs
Fig. 1 Flowchart of the literature search
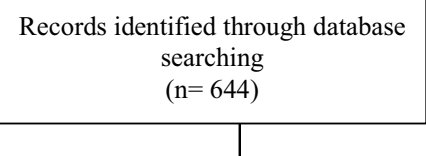

Records after duplicates removed $(\mathrm{n}=620)$
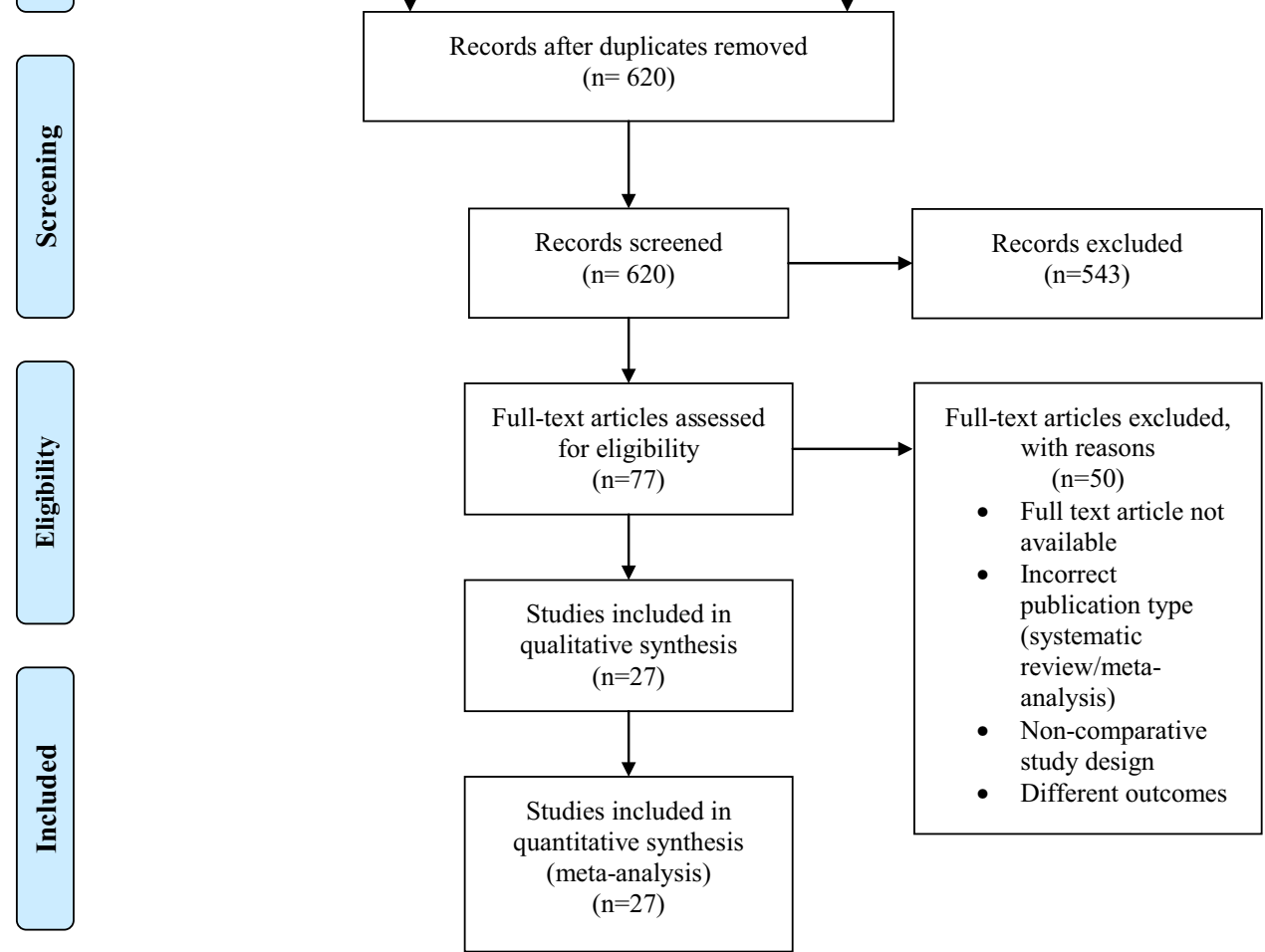


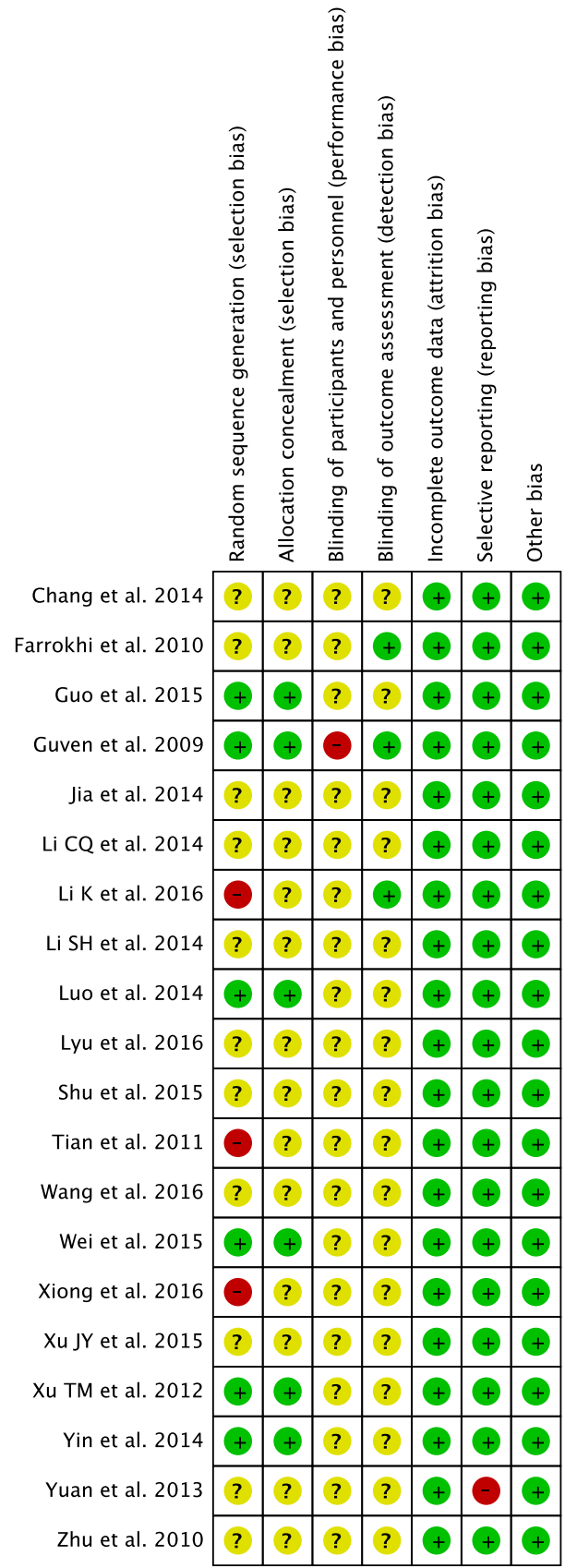

Fig. 2 Risk of bias summary: review of the authors' opinion on each risk of bias item for the included RCTs

the operation time significantly with a mean difference of $5.52 \min \left(95 \%\right.$ CI $0.79-10.26, P=0.02, I^{2}=87 \%$ ) (Fig. 3).

\section{Intraoperative blood loss}

Sixteen studies [1, 14, 15, 21-33] including 988 patients described the amount of blood loss during surgery. The pooled analysis of these results showed a mean difference of $25.30 \mathrm{~mL}$ of intraoperative blood loss, favouring the 4-screw construct significantly (95\% CI 6.91-44.20, $P<0.01, I^{2}=96 \%$ ) (Fig. 4).

\section{Hospital length of stay}

Information on hospital length of stay was provided in four studies $[14,15,21,26]$ (255 patients). The duration of hospital length of stay ranged from 8.7-13 days in the 6-screw group and 9-12.2 days in the 4-screw construct group. The mean difference regarding the hospital LOS was not significant (MD $0.44,95 \% \mathrm{CI}-0.68$ to $1.57, \mathrm{P}=0.44, \mathrm{I}^{2}=50 \%$ ) (Fig. 5).

\section{Visual analog scale}

Information on the VAS is provided in nine of the included studies [1, 14, 21-23, 27, 31, 34, 35] describing 501 patients. The VAS in these studies was rated at follow-up at least three months after surgery. The pooled results showed that the 6 -screw construct reduces the VAS significantly with a mean difference of 0.64 points ( $95 \% \mathrm{CI}-1.08$ to $-0.19, P<0.01$, $I^{2}=93 \%$ ) (Fig. 6).

\section{Oswestry disability index}

Information about ODI was extracted from five studies including 273 patients [14, 22, 23, 26, 31]. The ODI was determined at follow-up at more than one-year post-operative. The pooled results show no significant difference between the 6-screw and 4-screw construct group (MD $-0.19,95 \%$ CI -1.52 to $1.14, P=0.78, I^{2}=41 \%$ ) (Fig. 7 ).

\section{Short-term post-operative Cobb angle}

Fourteen studies [1, 15, 22-24, 27-29, 31, 32, 36-38] compared the short-term post-operative Cobb angle between the 4-screw and 6-screw construct group (713 patients). In these studies, the short-term post-operative Cobb angle was measured between 1 week and 1 month post-operative. Patients in the 6-screw construct group had significantly better shortterm post-operative Cobb angles with a mean difference of $1.07^{\circ}$ (95\% CI -1.82 to $-0.32, P<0.01, I^{2}=85 \%$ ) (Fig. 8).

\section{Long-term post-operative Cobb angle}

Post-operative Cobb angle measured at follow-up after one year has been described in thirteen studies (766 patients) $[1$, 21-23, 26-28, 30, 31, 34, 36-38]. The 6-screw construct showed significantly better results regarding the long-term post-operative Cobb angle with a mean difference of $3.69^{\circ}$ (95\% CI -5.20 to $-2,18, P<0.01, I^{2}=90 \%$ ) (Fig. 9). 
Table 1 Summary of evidence graded using the GRADE approach for the included RCTs

Summary of findings

The use of the 6-screw construct compared to the 4-screw construct for patients with thoracolumbar fractures

Population: Patients with thoracolumbar fractures

Intervention: 6-screw construct

Comparison: 4-screw construct

\begin{tabular}{|c|c|c|c|c|c|}
\hline \multirow[t]{2}{*}{ Outcomes } & \multicolumn{2}{|c|}{ Anticipated absolute effects (95\% CI) } & \multirow[t]{2}{*}{ Relative effect (95\% CI) } & \multirow{2}{*}{$\begin{array}{l}\text { Number of par- } \\
\text { ticipants (studies) }\end{array}$} & \multirow{2}{*}{$\begin{array}{l}\text { Quality of } \\
\text { the evidence } \\
\text { (GRADE) }\end{array}$} \\
\hline & $\begin{array}{l}\text { Risk with 4-screw con- } \\
\text { struct }\end{array}$ & $\begin{array}{l}\text { Risk with 6-screw con- } \\
\text { struct }\end{array}$ & & & \\
\hline $\begin{array}{l}\text { Operation time assessed } \\
\text { with (min) }\end{array}$ & $\begin{array}{l}\text { The mean operation time } \\
\text { was } 92.8 \mathrm{~min}\end{array}$ & $\begin{array}{l}\text { MD } 3.88 \text { longer [ } 0.89 \text {, } \\
8.65]\end{array}$ & & 748 (12 studies) & $\underset{\text { Moderate }^{\mathrm{b}}}{\bigoplus \bigoplus \bigoplus}$ \\
\hline $\begin{array}{l}\text { Intraoperative blood loss } \\
\text { assessed with }(\mathrm{mL})\end{array}$ & $\begin{array}{l}\text { The mean intraop- } \\
\text { erative blood loss was } \\
280.3 \mathrm{~mL}\end{array}$ & $\begin{array}{l}\text { MD } 28.29 \text { higher [5.97, } \\
50.61]\end{array}$ & & 808 (13 studies) & $\begin{array}{l}\bigoplus \bigoplus \bigoplus \bigcirc \\
\text { Moderate }^{\mathrm{b}}\end{array}$ \\
\hline $\begin{array}{l}\text { Hospital length of stay } \\
\text { assessed with (days) }\end{array}$ & $\begin{array}{l}\text { The mean hospital length } \\
\text { of stay was } 9.6 \text { days }\end{array}$ & $\begin{array}{l}\text { MD } 0.35 \text { longer [ }-1.36 \text {, } \\
2.07]\end{array}$ & - & 186 (3 studies) & 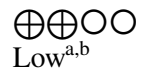 \\
\hline VAS & The mean VAS was 2.77 & $\begin{array}{l}\text { MD } 0.87 \text { lower }[-1.46 \\
-0.28]\end{array}$ & - & 388 (7 studies) & 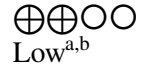 \\
\hline ODI & The mean ODI was 18.8 & $\begin{array}{l}\text { MD } 0.97 \text { lower [- 2.46, } \\
0.53]\end{array}$ & - & 160 (3 studies) & $\underset{\text { Moderate }^{\mathrm{a}}}{\bigoplus \bigoplus \bigoplus \bigcirc}$ \\
\hline $\begin{array}{l}\text { Short-term post-operative } \\
\text { Cobb angle in degrees }\end{array}$ & $\begin{array}{l}\text { The mean short-term } \\
\text { post-operative Cobb } \\
\text { angle was } 5.18 \text { degrees }\end{array}$ & $\begin{array}{l}\text { MD 1.02 lower [-2.46, } \\
0.53]\end{array}$ & - & 607 (11 studies) & $\begin{array}{l}\bigoplus \bigoplus \bigoplus \bigcirc \\
\text { Moderate }^{\mathrm{b}}\end{array}$ \\
\hline $\begin{array}{l}\text { Long-term post-operative } \\
\text { Cobb angle in degrees }\end{array}$ & $\begin{array}{l}\text { The mean long-term post- } \\
\text { operative Cobb angle } \\
\text { was } 11.16 \text { degrees }\end{array}$ & $\begin{array}{l}\text { MD } 3.76 \text { lower }[-5.69 \\
\quad-1.82]\end{array}$ & - & 692 (11 studies) & $\begin{array}{l}\bigoplus \bigoplus \bigoplus \bigcirc \\
\text { Moderate }^{\mathrm{b}}\end{array}$ \\
\hline $\begin{array}{l}\text { Correction loss of Cobb } \\
\text { angle in degrees }\end{array}$ & $\begin{array}{l}\text { The mean correction loss } \\
\text { of Cobb angle was } 4.22 \\
\text { degrees }\end{array}$ & $\begin{array}{l}\text { MD } 1.78 \text { lower }[-3.4 \\
-0.15]\end{array}$ & - & 254 (5 studies) & $\underset{\text { Moderate }^{\mathrm{b}}}{\bigoplus \bigoplus \bigoplus}$ \\
\hline $\begin{array}{l}\text { Correction loss of AVBH } \\
\text { in degrees }\end{array}$ & $\begin{array}{l}\text { The mean correction loss } \\
\text { of AVBH was } 8.84 \\
\text { degrees }\end{array}$ & $\begin{array}{l}\text { MD } 6.01 \text { lower }[-7.66 \text {, } \\
-4.36]\end{array}$ & - & 566 (8 studies) & $\underset{\text { Moderate }^{\mathrm{b}}}{\bigoplus \bigoplus \bigoplus \bigcirc}$ \\
\hline Implant failure & 75 per 1000 & 13 per $1000[6,27]$ & OR $0.16[0.07,0.34]$ & 1104 (16 studies) & $\underset{\text { Moderate }^{c}}{\bigoplus \bigoplus \bigoplus \bigcirc}$ \\
\hline Post-operative infection & 23 per 1000 & 17 per 1000) $[5,57]$ & OR $0.74[0.21,2.55]$ & 506 (9 studies) & $\begin{array}{l}\bigoplus \bigoplus_{L^{a}, \mathrm{c}} \bigcirc \bigcirc \\
\end{array}$ \\
\hline
\end{tabular}

$C I$ confidence interval, $O R$ odds ratio, $M D$ mean difference, $A V B H$ anterior vertebral body height, $V A S$ visual analogue scale, $O D I$ oswestry disability index, RCTs randomized controlled trials

GRADE working group grades of evidence

High quality: We are very confident that the true effect lies close to that of the estimate of the effect

Moderate quality: We are moderately confident in the effect estimate: The true effect is likely to be close to the estimate of the effect, but there is a possibility that it is substantially different

Low quality: Our confidence in the effect estimate is limited: The true effect may be substantially different from the estimate of the effect

Very low quality: We have very little confidence in the effect estimate: The true effect is likely to be substantially different from the estimate of effect

${ }^{a}$ Risk of bias: subjective outcome and no blinding of participants/study personnel, ${ }^{b}$ Inconsistency: large variations in effect, large $\mathrm{I}^{2}$, ${ }^{\mathrm{c}}$ Imprecision: low rate of events, large confidence intervals. No downgrading for indirectness or publication bias

\section{Correction loss of Cobb angle}

Seven of the included studies $[1,15,22,23,25,32,38]$ provide information on the correction loss of Cobb angle in the 6-screw and 4-screw construct group (351 patients). The 6-screw method leads to a significantly lower correction loss of Cobb angle (MD $-1.95,95 \% \mathrm{CI}-3.10$ to -0.79 , $P<0.01, I^{2}=87 \%$ ) (Fig. 10). 


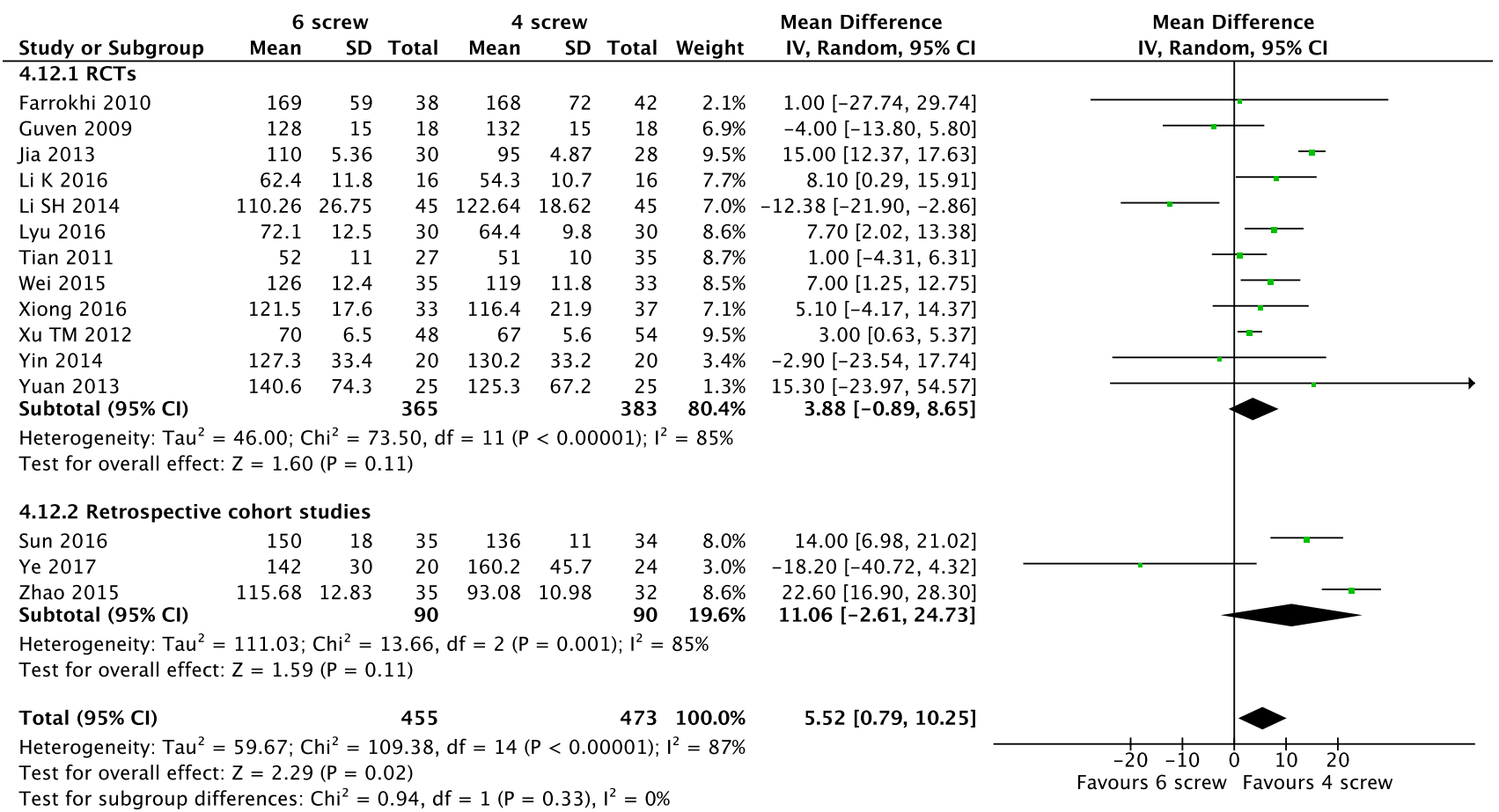

Fig. 3 Forest plot comparing operation time for $6 \mathrm{~S}$ versus $4 \mathrm{~S}$. $R C T$ s randomized controlled trials, $C I$ confidence interval, $I V$ inverse variance, $S D$ standard deviation

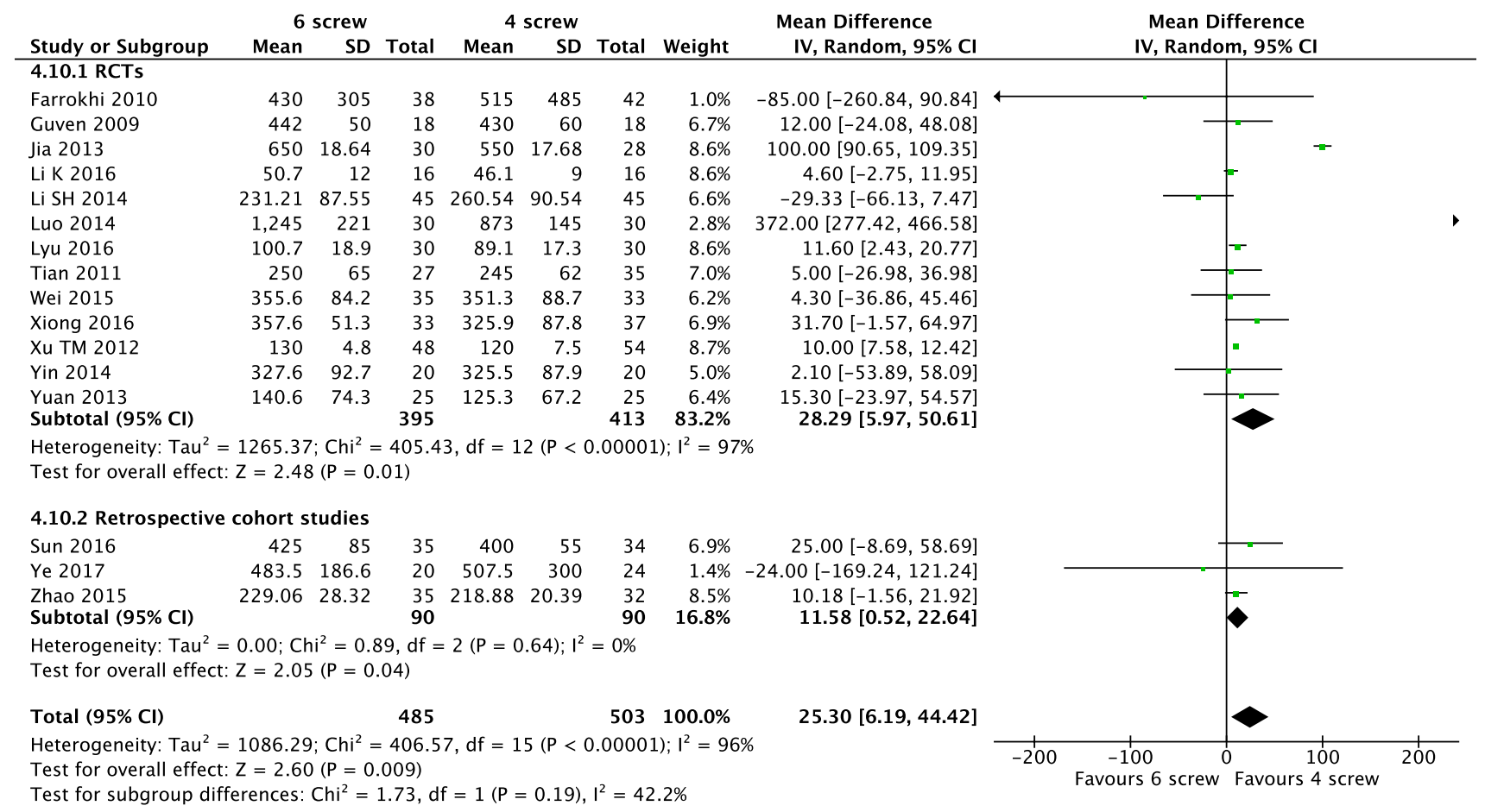

Fig. 4 Forest plot comparing intraoperative blood loss for $6 \mathrm{~S}$ versus $4 \mathrm{~S}$. RCTs randomized controlled trials, $C I$ confidence interval, $I V$ inverse variance, $S D$ standard deviation 


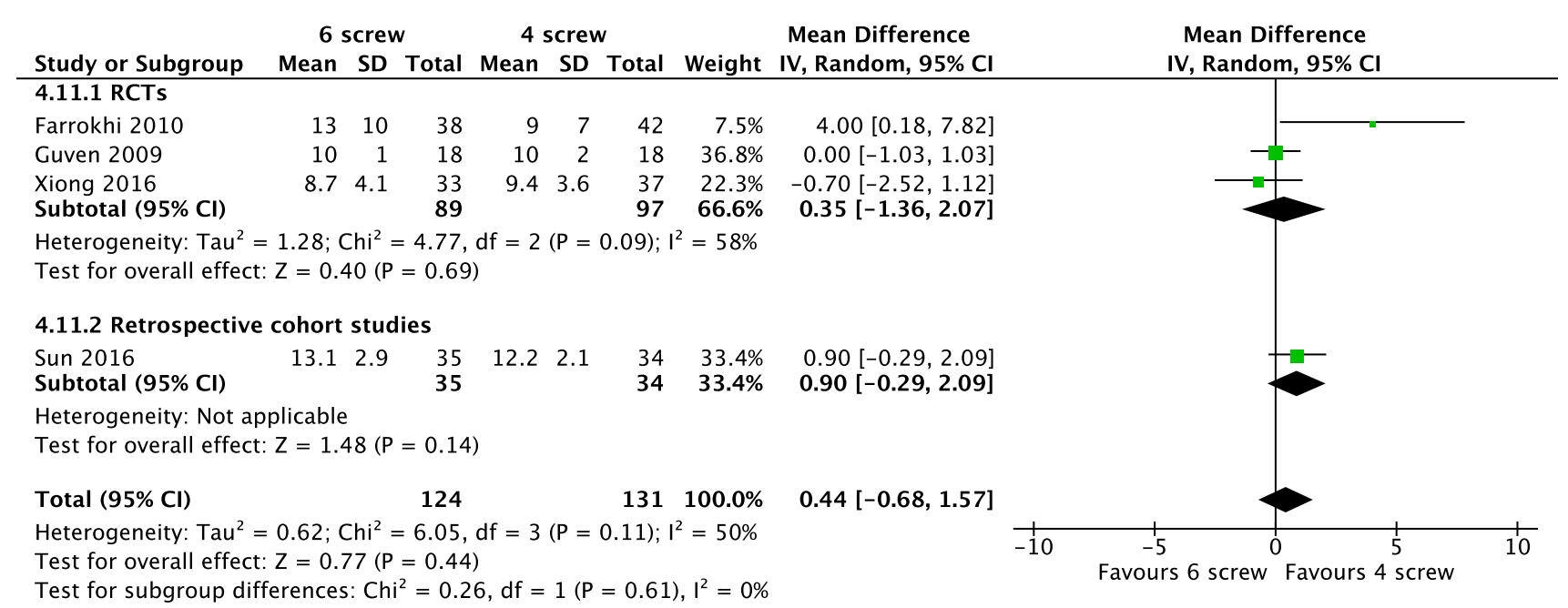

Fig. 5 Forest plot comparing hospital length of stay for $6 \mathrm{~S}$ versus $4 \mathrm{~S}$. $R C T s$ randomized controlled trials, $C I$ confidence interval, $I V$ inverse variance, $S D$ standard deviation

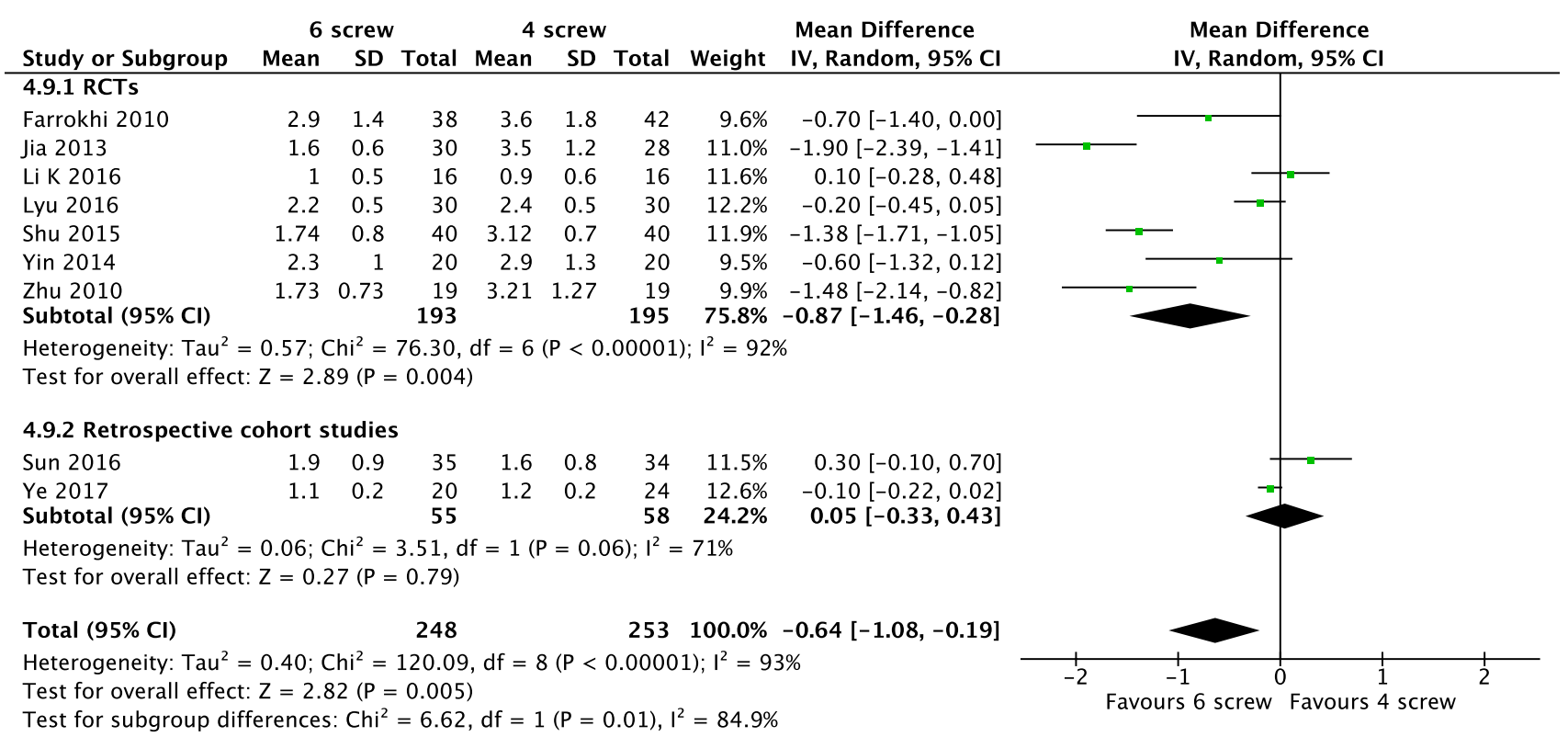

Fig. 6 Forest plot comparing visual analog scale for $6 \mathrm{~S}$ versus $4 \mathrm{~S}$. RCTs randomized controlled trials, $C I$ confidence interval, $I V$ inverse variance, $S D$ standard deviation

\section{Correction loss of anterior vertebral body height}

Twelve studies [14, 22, 23, 25, 26, 32, 33, 38-42] describe values for the correction loss of anterior vertebral height of the 4- and 6-screw construct groups (862 patients). A meta-analysis of these values shows that the 6-screw construct leads to a significantly lower correction loss of the AVBH than the 4-screw method with a mean difference of $4.36 \mathrm{~mm}$ (95\% CI -6.56 to $\left.-2.16, P<0.01, I^{2}=98 \%\right)$

(Fig. 11).

\section{Implant failure}

Twenty studies [1, 14, 15, 21-30, 32-34, 39, 40, 42, 43] describe rates of post-operative implant failure (1514 patients). The pooled results show that a significantly lower rate of implant failure was seen in the 6-screw construct group with an OR of 0.26 (95\% CI $0.15-0.47$, $P<0.01, I^{2}=0 \%$ ) (Fig. 12). 


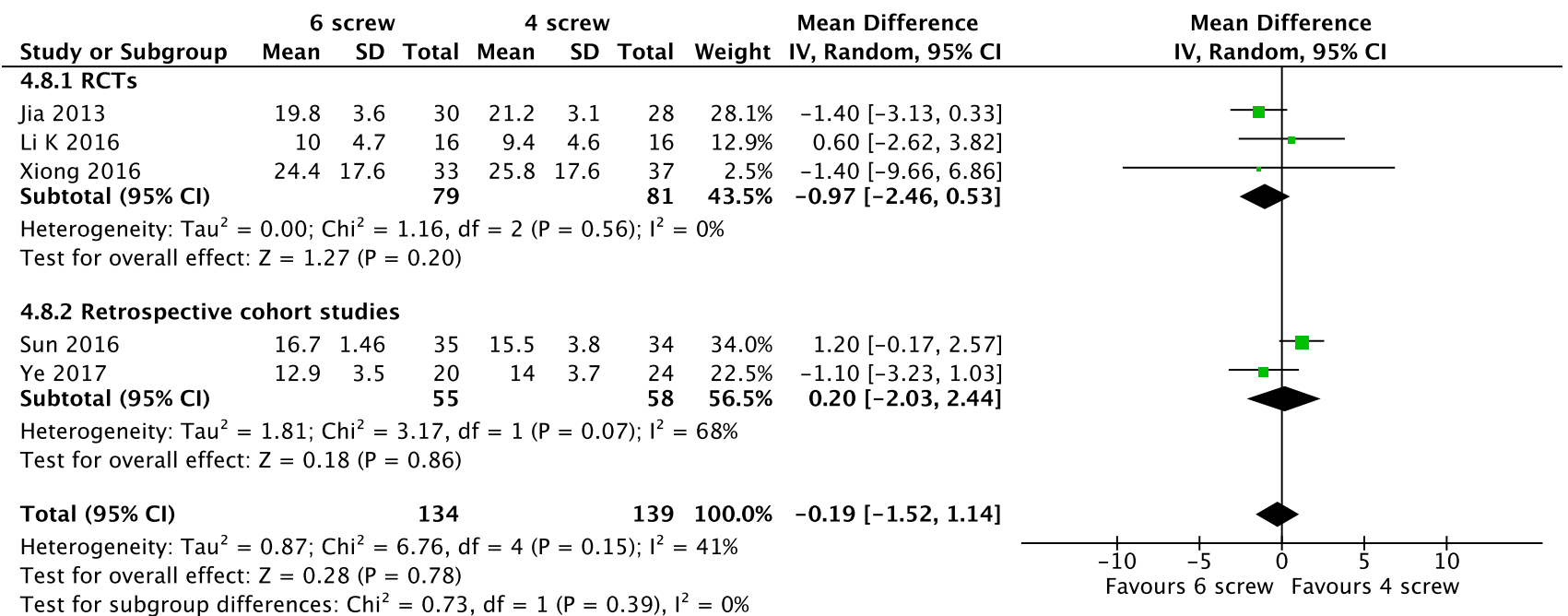

Fig. 7 Forest plot comparing Oswestry Disability Index for $6 \mathrm{~S}$ versus $4 \mathrm{~S}$. $R C T s$ randomized controlled trials, $C I$ confidence interval, $I V$ inverse variance, $S D$ standard deviation

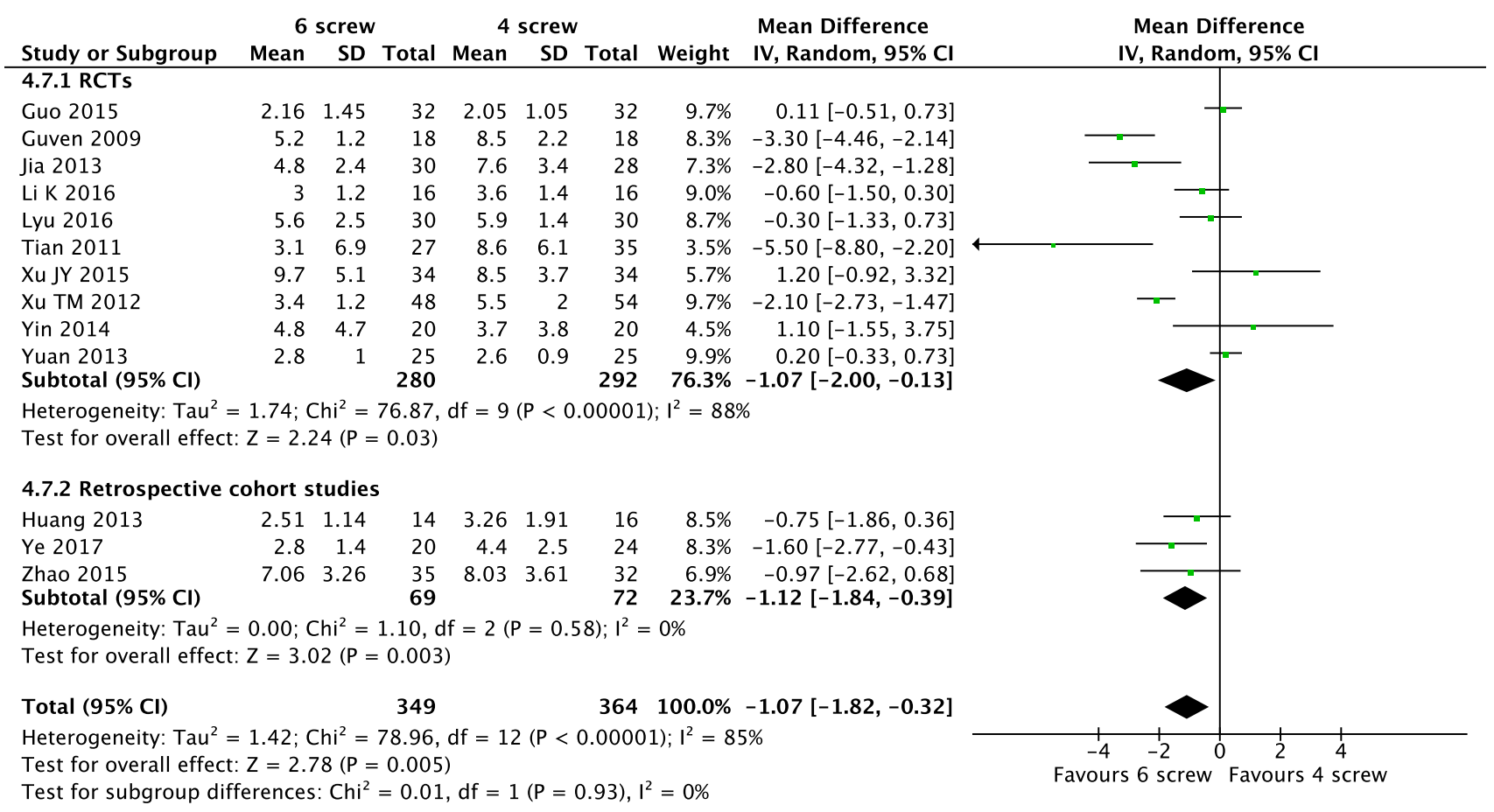

Fig. 8 Forest plot comparing short-term post-operative Cobb angle for $6 \mathrm{~S}$ versus $4 \mathrm{~S}$. RCTs randomized controlled trials, $C I$ confidence interval, $I V$ inverse variance, $S D$ standard deviation

\section{Post-operative infection}

Information on post-operative infections is provided in twelve studies [1, 14, 15, 21-27, 31, 43] (765 patients). Fixed-effect analysis showed no significant difference between the groups concerning infections post-operatively (OR $0.66,95 \%$ CI 0.21 to $2.07, P=0.47, I^{2}=0 \%$ ) (Fig. 13).

\section{Subgroup analysis}

Three of the included studies used a percutaneous technique for the pedicle screw fixation and 24 studies applied an open surgical technique, including 226 and 1654 patients, respectively. A subgroup analysis was performed to analyse the outcomes for the open and percutaneous surgical technique separately. For the open surgical technique, the pooled 


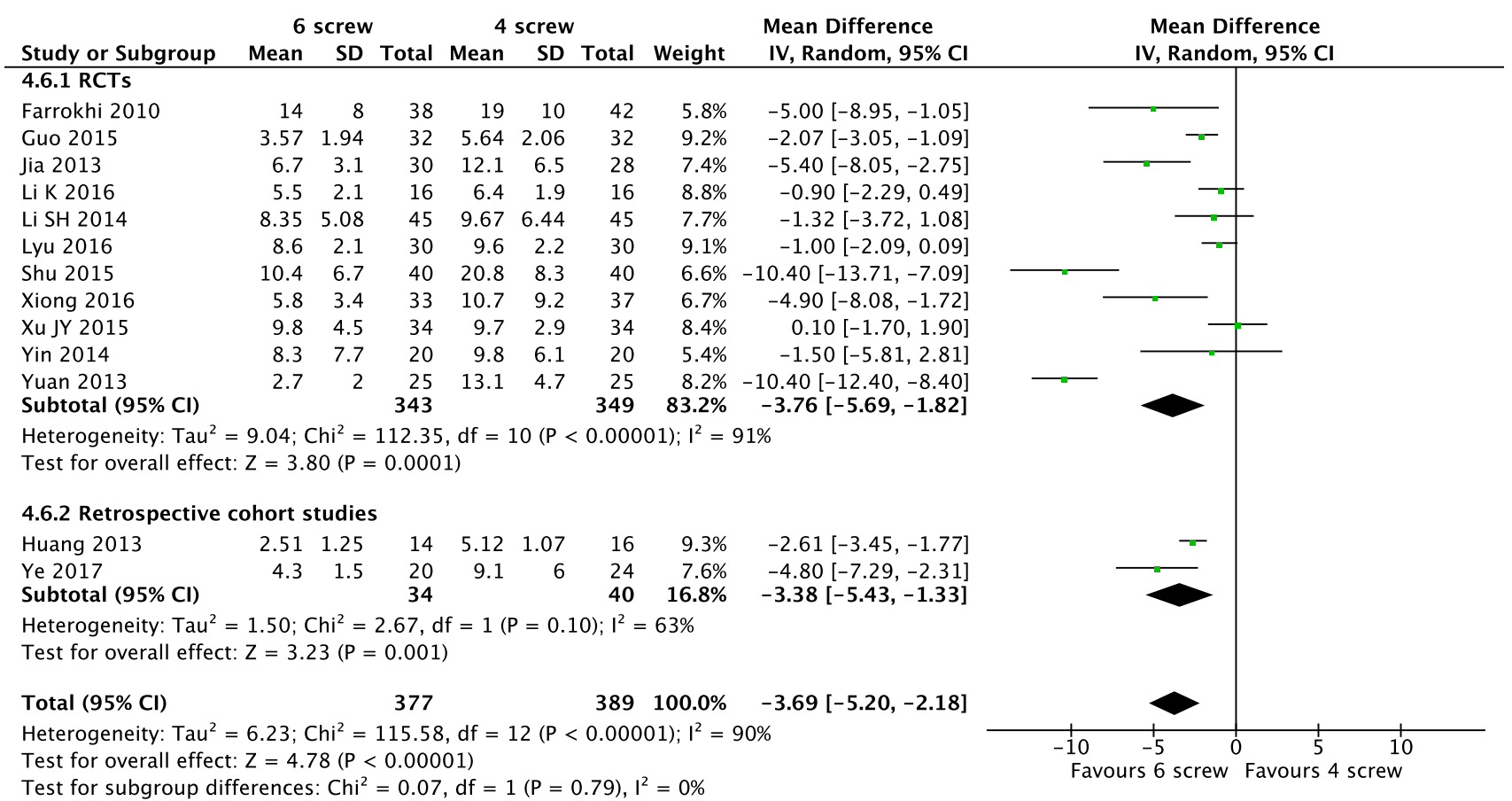

Fig. 9 Forest plot comparing long-term post-operative Cobb angle for $6 \mathrm{~S}$ versus $4 \mathrm{~S}$. RCTs randomized controlled trials, $C I$ confidence interval, $I V$ inverse variance, $S D$ standard deviation

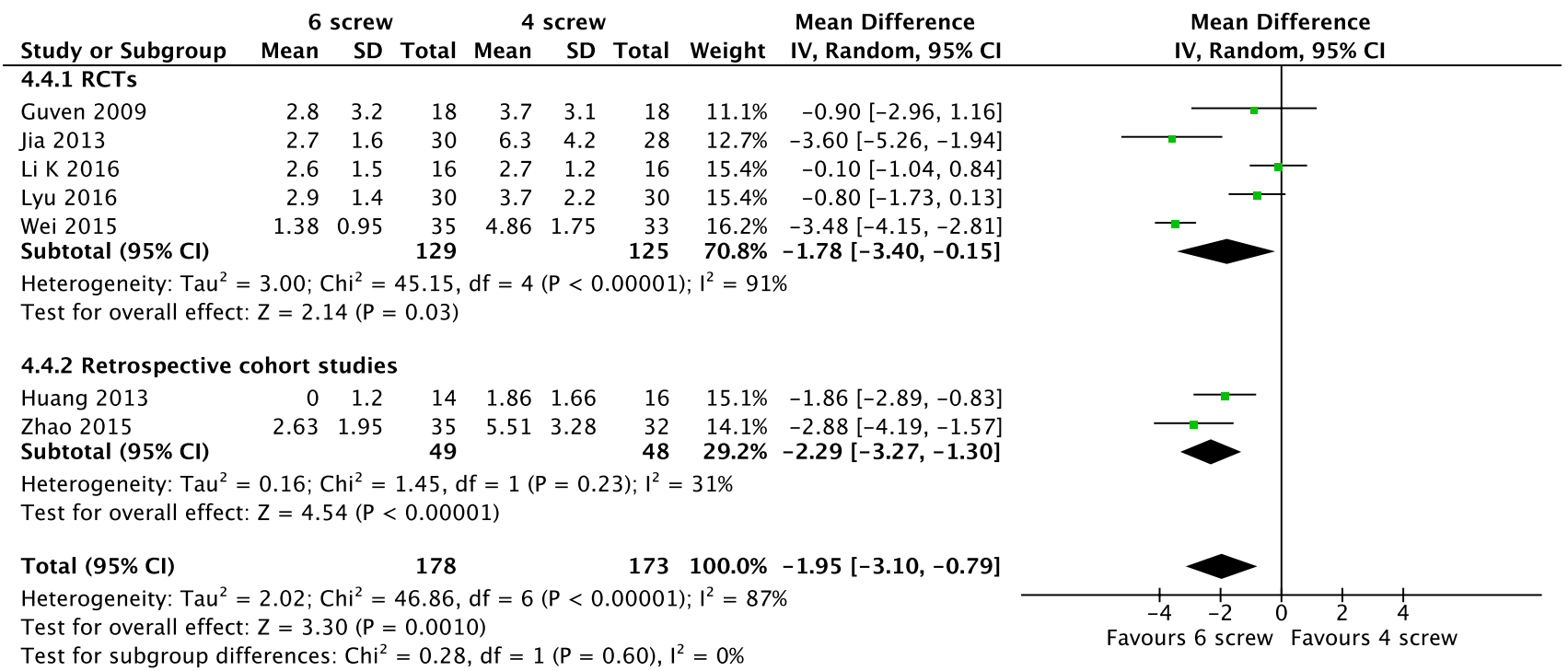

Fig. 10 Forest plot comparing correction loss of Cobb angle for $6 \mathrm{~S}$ versus $4 \mathrm{~S}$. RCTs randomized controlled trials, $C I$ confidence interval, $I V$ inverse variance, $S D$ standard deviation

data on the VAS, short-term and long-term post-operative Cobb angle, correction loss of Cobb angle and AVBH and implant failure all showed significant results favouring the 6-screw construct group. A significantly higher blood loss, but no significantly longer operation time was seen in the 6 -screw construct with the open technique. For the percutaneous technique, a significantly longer operation time and significantly better results of long-term Cobb angle and correction loss of AVBH were seen in the 6-screw group compared to the 4-screw group. For the percutaneous technique, the 6-screw construct did not result in an increase in blood loss compared to the 4 -screw construct. For the outcomes ODI and post-operative infection, the pooled analysis showed no significant difference between the 6 -screw and 


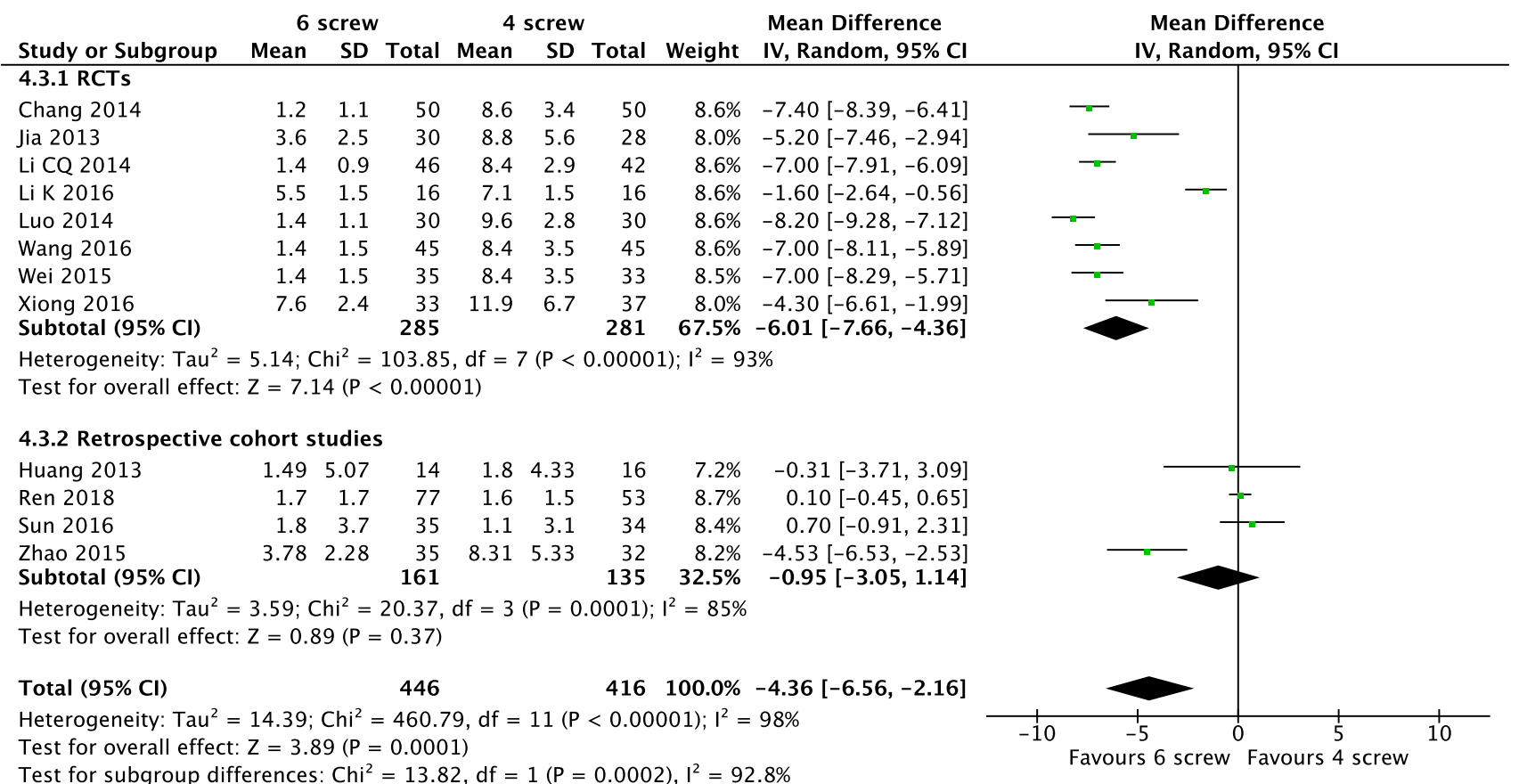

Fig. 11 Forest plot comparing correction loss of anterior vertebral body height for $6 \mathrm{~S}$ versus $4 \mathrm{~S}$. RCTs randomized controlled trials, $C I$ confidence interval, $I V$ inverse variance, $S D$ standard deviation

4-screw construct group for both percutaneous and open techniques. No studies describing the hospital length of stay made use of the percutaneous surgical technique.

\section{Discussion}

In this systematic review, short-segment fixation (4S construct) was compared to short-segment fixation with additional intermediate screws at the fracture level (6S construct) in the treatment of thoracolumbar fractures.

The results from our meta-analysis reveal that a $6 \mathrm{~S}$ construct significantly improves outcomes concerning postoperative pain, short-term and long-term Cobb angles, correction loss of Cobb angle and AVBH and implant failure. Although these results were significantly better in $6 \mathrm{~S}$ compared to $4 \mathrm{~S}$ patients, questions remain about the clinical relevance of these differences. The mean difference in VAS of 0.64 and the mean gain in short-term Cobb angle of 1 degree were statistically significant in favour of the $6 \mathrm{~S}$. The clinical impact of these small differences, however, remains questionable. The mean difference in long-term Cobb angle of almost 4 degrees and an odds ratio of 0.26 for implant failure seems to be more clinically relevant. This, however, did not result in a significant difference in the measured ODI scores after one year, which may be explained by the fact that the ODI was only studied in 3 RCTs and 2 retrospective studies with a total of 273 patients. The clinical impact of a prolongation of the operation duration with a mean of approximately $6 \mathrm{~min}$ and a higher blood loss of $25.30 \mathrm{~mL}$ also remains questionable. Although $6 \mathrm{~S}$ constructs seem to have small but significantly better results on many outcomes, future studies should focus more on patient-reported outcomes and quality of life measurements, in which the benefits and risks should be weighted in a cost-effectiveness analysis [44].

Our meta-analysis shows significantly better results concerning radiological outcomes and implant failure in the $6 \mathrm{~S}$ construct. These results can be explained by the fact that placement of intermediate screws at the fracture level improves the construct rigidity and stiffness, as described in several biomechanical studies [8-12, 45]. A study by Dobran et al. showed that short-segment fixation with intermediate screws provides radiological results similar to long-segment posterior fixation in which 2 levels above and 2 levels below the fracture are fixated [46]. However, a short-segment 6-screw construct could decrease the size of the immobilized segment and therefore retains more spinal motion compared to a long-segment fixation. Moreover, 6 instead of 8 screws are needed in a short-segment $6 \mathrm{~S}$ construct and when an open technique is used, a smaller incision size will be necessary [47].

Klezl et al. showed that the addition of vertebral body stenting (VBS) in posterior stabilization could also lead to improvement in pain and functional outcomes [48]. The study by Pflugmacher et al. presented similar improved 


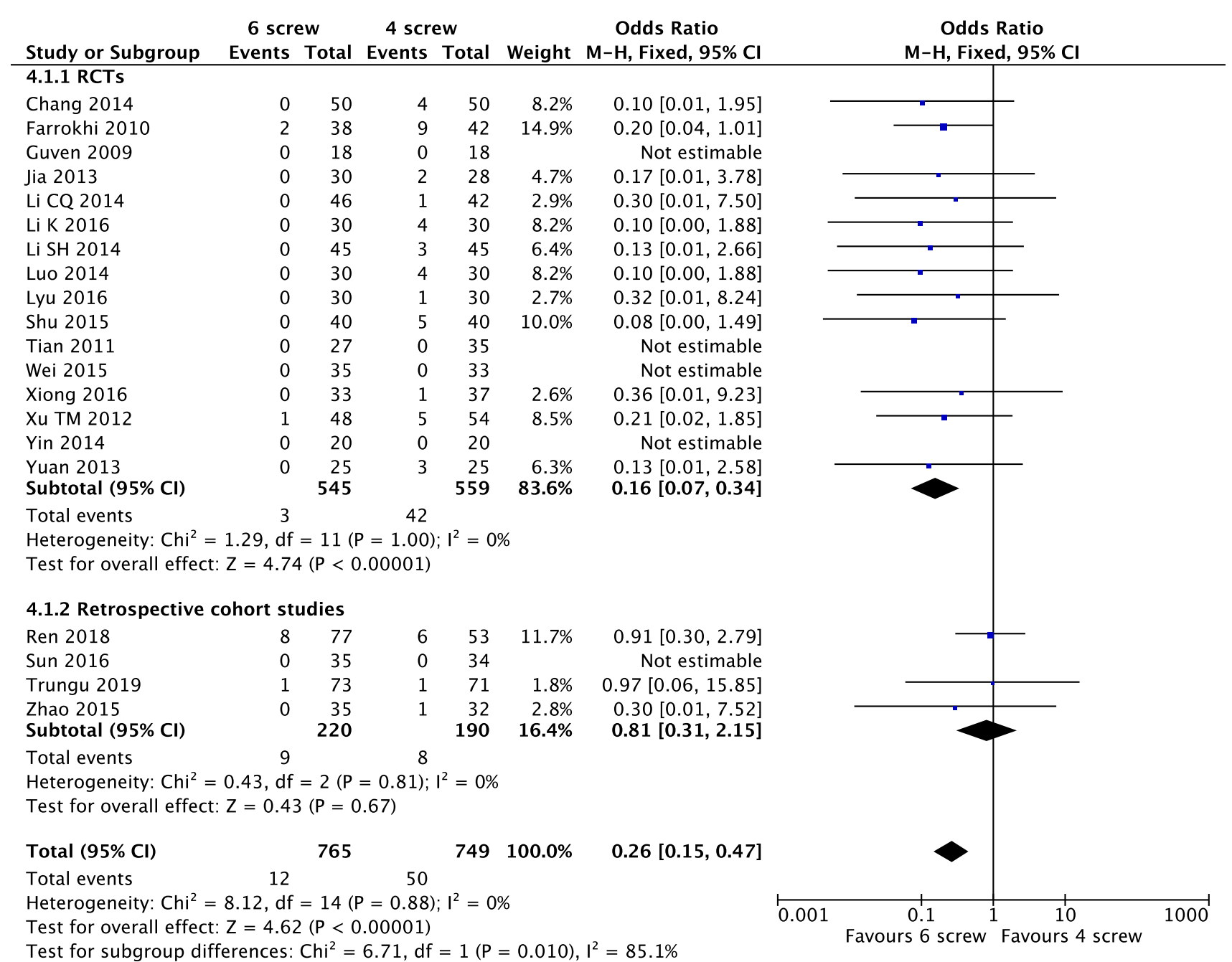

Fig. 12 Forest plot comparing implant failure for $6 \mathrm{~S}$ versus $4 \mathrm{~S}$. RCTs randomized controlled trials, $C I$ confidence interval, $I V$ inverse variance, $S D$ standard deviation

results for balloon kyphoplasty combined with posterior instrumentation [49]. Bornemann et al. demonstrated that radiofrequency kyphoplasty in combination with posterior fixation also leads to better results on VAS and ODI scores than with posterior fixation alone [50]. Posterior short-segment fixation with intermediate screws was compared to short-segment fixation with balloon kyphoplasty by Zhang et al. Their study showed peri-operative results favouring intermediate screws but clinical and radiological outcomes favouring balloon kyphoplasty [51]. Future studies on a combination of posterior short-segment fixation with kyphoplasty and intermediate screws through the kyphoplasty cement might be interesting. However, the relation of VBS, balloon kyphoplasty and radiofrequency kyphoplasty to short-segment posterior fixation with intermediate screws in terms of peri-operative, clinical and radiological outcomes requires further elucidation to draw definite conclusions.

Although 28 studies were performed on the use of intermediate screws, no literature exists on the ideal characteristics of these intermediate screws. In our included literature, different types and sizes of screws were used as intermediate screws. Guven et al. and Chang et al. used shorter screws in the fractured vertebra compared to the screws in the non-fractured vertebra $[15,39]$. The 6 -screw construct by Farrokhi et al. used all same size screws [21]. Poly-axial intermediate screws were used by Sun et al., whereas monoaxial intermediate screws were used by Guven et al. [14, 15]. Hence, there is no consensus on what size and type of intermediate screw are the most favourable. Future (biomechanical) studies are needed on this topic.

The results of our systematic review and meta-analysis are in line with previous and smaller systematic reviews 


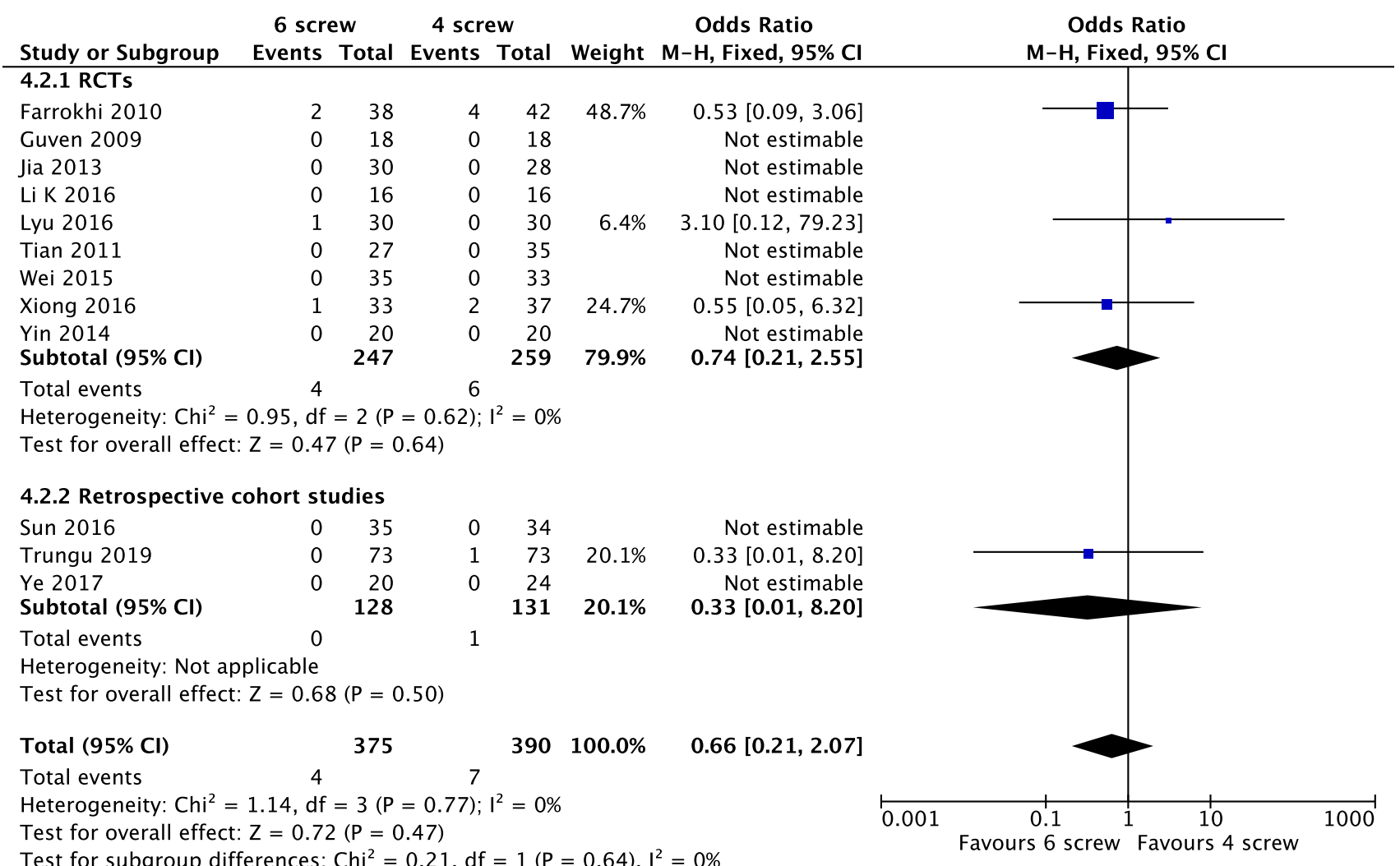

Fig. 13 Forest plot comparing post-operative infection for $6 \mathrm{~S}$ versus $4 \mathrm{~S}$. RCTs randomized controlled trials, $C I$ confidence interval, $I V$ inverse variance, $S D$ standard deviation

comparing $4 \mathrm{~S}$ construct with the $6 \mathrm{~S}$ construct [52-54]. However, these previous reviews were no longer up to date (included studies until 2017) or did not include all available data due to a language restriction. To date, this is the first and largest review in which all available and up to date literature on this topic is included. Both RCTs and retrospective cohort studies were included in this systematic review, but a subgroup meta-analysis was performed for RCTs and retrospective studies. For most outcomes, the meta-analysis for the RCT and retrospective studies corresponded well; therefore, results from the retrospective studies seem to be reliable and valuable for the overall meta-analysis.

This review still has some limitations. Although most studies were randomized controlled trials, sample sizes were small and in most studies, the type of randomization was not clearly stated or mentioned at all. This potential risk of bias together with the non-blinded fashion both devaluated the quality of evidence in the GRADE, especially for the outcomes that were subjective, or patient reported. Together with the statistical heterogeneity $\left(I^{2}\right)$, this led to the devaluation of the quality of evidence for most outcomes to "moderate" or "low".

Moreover, the included studies seem to have heterogeneous populations with different indications for posterior fixation. Although all studies included fractures from level T10 to L5, different fracture types with different classification systems (type $\mathrm{A}, \mathrm{B}$ or $\mathrm{C}$ according to AO/Magerl and type A, B, C or D according to Denis) and patients different neurological status (Frankel A to E) were included in the different studies. Some studies even did not explicitly describe the number of patients in each fracture type or neurological status at all. Mahar et al. showed that the placement of screws at fracture level improves construct rigidity and shields the fractured vertebra from anterior loads [45]. Therefore, especially comminuted fractures that are less stable due to lack of anterior support might benefit more from rigid constructions with intermediate screws. Future studies should direct at which type of fractures benefit the most from 6-screw constructs.

The use of open and percutaneous techniques also implied heterogeneity and poses another limitation of this review. The majority of the included studies used an open technique, while only 3 used a percutaneous technique. Previous studies have shown that percutaneous techniques might result in better outcomes than open techniques, regardless of the placement of additional screws [55]. Besides, a $6 \mathrm{~S}$ construct might have different impact in percutaneous surgery than in open surgery. Our subgroup 
analysis group showed less differences between the $4 \mathrm{~S}$ and $6 \mathrm{~S}$ constructs in percutaneous surgery, but this might be the result of smaller sample sizes and therefore statistically insignificance.

\section{Conclusion}

This systematic review and meta-analysis show that in the treatment of thoracolumbar fractures, the addition of intermediate screws at the fractured level results in significantly less post-operative pain, better radiological outcomes and less implant failure at the cost of a longer operation time and higher blood loss. However, most differences in outcome were small and the overall quality of the evidence was moderate to low. More studies on this topic are needed and should be directed more at patient reported outcomes and at which specific fracture types benefit the most from intermediate screws.

Funding The authors received no specific funding for this work.

\section{Compliance with ethical standards}

Conflict of interest The authors declare that they have no conflict of interest.

Open Access This article is licensed under a Creative Commons Attribution 4.0 International License, which permits use, sharing, adaptation, distribution and reproduction in any medium or format, as long as you give appropriate credit to the original author(s) and the source, provide a link to the Creative Commons licence, and indicate if changes were made. The images or other third party material in this article are included in the article's Creative Commons licence, unless indicated otherwise in a credit line to the material. If material is not included in the article's Creative Commons licence and your intended use is not permitted by statutory regulation or exceeds the permitted use, you will need to obtain permission directly from the copyright holder. To view a copy of this licence, visit http://creativecommons.org/licenses/by/4.0/.

\section{References}

1. Lyu J, Chen K, Tang Z, Chen Y, Li M, Zhang Q (2016) A comparison of three different surgical procedures in the treatment of type A thoracolumbar fractures: a randomized controlled trial. Int Orthop 40(6):1233-1238

2. Mohanty SP, Bhat SN, Ishwara-Keerthi C (2011) The effect of posterior instrumentation of the spine on canal dimensions and neurological recovery in thoracolumbar and lumbar burst fractures. Musculoskelet Surg 95(2):101-106

3. Torio T, Kikkawa J, Kannari F, Suzuki K, Nemoto M, Oda H (2017) Short segment pedicle screw fixation by using additional screws at the fracture level-for the fixation of thoracolumbar burst fractures. J Saitama Med Univ 43(2):155-161
4. McLain RF, Sparling E, Benson DR (1993) Early failure of shortsegment pedicle instrumentation for thoracolumbar fractures: a preliminary report. J Bone Joint Surg Am 75(2):162-167

5. Parker JW, Lane JR, Karaikovic EE, Gaines RW (2000) Successful short-segment instrumentation and fusion for thoracolumbar spine fractures: a consecutive 41/2-year series. Spine (Phila Pa 1976) 25(9): 1157-1170

6. Wood KB, Bohn D, Mehbod A (2005) Anterior versus posterior treatment of stable thoracolumbar burst fractures without neurologic deficit: a prospective, randomized study. J Spinal Disord Tech 18:S15-S23

7. Scholl BM, Theiss SM, Kirkpatrick JS (2006) Short segment fixation of thoracolumbar burst fractures. Orthopedics 29(8):703-708

8. Dick JC, Jones MP, Zdeblick TA, Kunz DN, Horton WC (1994) A biomechanical comparison evaluating the use of intermediate screws and cross-linkage in lumbar pedicle fixation. J Spinal Disord 7(5):402-407

9. Norton RP, Milne EL, Kaimrajh DN, Eismont FJ, Latta LL, Williams SK (2014) Biomechanical analysis of four- versus six-screw constructs for short-segment pedicle screw and rod instrumentation of unstable thoracolumbar fractures. Spine J 14(8):1734-1739

10. Baaj AA, Reyes PM, Yaqoobi AS, Uribe JS, Vale FL, Theodore N et al (2011) Biomechanical advantage of the index-level pedicle screw in unstable thoracolumbar junction fractures. J Neurosurg Spine 14(2):192-197

11. Bolesta MJ, Caron T, Chinthakunta SR, Vazifeh PN, Khalil S (2012) Pedicle screw instrumentation of thoracolumbar burst fractures: Biomechanical evaluation of screw configuration with pedicle screws at the level of the fracture. Int J spine Surg 6:200-205

12. Wang H, Li C, Liu T, Zhao WD, Zhou Y (2012) Biomechanical efficacy of monoaxial or polyaxial pedicle screw and additional screw insertion at the level of fracture, in lumbar burst fracture: an experimental study. Indian J Orthop 46(4):395-401

13. Li C, Zhou Y, Wang H, Liu J, Xiang L (2014) Treatment of unstable thoracolumbar fractures through short segment pedicle screw fixation techniques using pedicle fixation at the level of the fracture: a finite element analysis. PLoS One 9(6):e99156

14. Sun C, Guan G, Liu X, Zhang H, Wang B (2016) Comparison of short-segment pedicle fixation with versus without inclusion of the fracture level in the treatment of mild thoracolumbar burst fractures. Int J Surg 36(Pt A):352-357

15. Guven O, Kocaoglu B, Bezer M, Aydin N, Nalbantoglu U (2009) The use of screw at the fracture level in the treatment of thoracolumbar burst fractures. J Spinal Disord Tech 22(6):417-421

16. Farrokhi M-R, Razmkon A, Maghami Z, Nikoo Z (2010) Inclusion of the fracture level in short segment fixation of thoracolumbar fractures. Eur spine J Off Publ Eur Spine Soc Eur Spinal Deform Soc Eur Sect Cerv Spine Res Soc 19(10):1651-1656

17. Moher D, Liberati A, Tetzlaff J, Altman DG (2009) Preferred reporting items for systematic reviews and meta-analyses: the PRISMA statement. PLoS Med 6(7):336-341

18. Higgins JP (2011) Cochrane handbook for systematic reviews of interventions

19. Review Manager (RevMan) [Computer program]. Version 5.3. Copenhagen: The Nordic Cochrane Centre, The Cochrane Collaboration, 2014.

20. Borenstein M, Hedges LV, Higgins JPT, Rothstein HR (2009) Fixed-effect versus random-effects models

21. Farrokhi M-RR, Razmkon A, Maghami Z, Nikoo Z (2010) Inclusion of the fracture level in short segment fixation of thoracolumbar fractures. Eur spine J Off Publ Eur Spine Soc Eur Spinal Deform Soc Eur Sect Cerv Spine Res Soc. 19(10):1651-1656

22. Jia QY, Wang L, Yu Y, Guo WG, Yang N (2014) Clinical comparative study of short-segment fixation for thoracolumbar burst fracture via or not via injured vertebra. Chin J Bone Jt Inj 29(9):869-871 
23. Li K, Li Z, Ren X, Xu H, Zhang W, Luo D et al (2016) Effect of the percutaneous pedicle screw fixation at the fractured vertebra on the treatment of thoracolumbar fractures. Int Orthop 40(6):1103-1110

24. Tian J, Wang L, Xia T, Liu C, Zhao Q, Dong S (2011) Posterior short-segmental fixation combined with intermediate screws vs conventional intersegmental fixation for monosegmental thoracolumbar fractures. Orthopedics 34(8):e389-e39

25. Wei M, Liu Z, Liao WB, Zeng YG, Wu GH et al (2015) Pedicle screw fixation through the fracture vertebra with across the fracture level for thoracolumbar fractures. Guangxi Med J 37(5):712-713

26. Xiong J, Song ZH (2016) Compare the short segment internal fixation at fracture vertebra with not at fracture level for treatment of thoracolumbar fractures. J Pract Orthop 22(1):46-49

27. Yin F, Sun Z, Yin Q, Liu J, Gu S, Zhang S (2014) A comparative study on treatment of thoracolumbar fracture with injured vertebra pedicle instrumentation and cross segment pedicle instrumentation. Chin J Repar Reconstr Surg 28(2):227-232

28. Yuan ZF, Shao B, Zeng JP (2013) Pedicle screw fixation at the fracture vertebrae in the treatment of thoracolumbar fractures. $J$ Spinal Surg 11(1):32-35

29. Xu TM, Xu YQ, Chen JM, Zhang CC, Li Y, Li ZQ et al (2012) Short-segment pedicle screw fixation with screw placed at single injured vertebrae combined with transpedicular intracorporeal grafting for thoracolumbar fractures. Chin J Bone Jt Inj 27(9):789-791

30. Li SH, Tang YZ, Yang LQ, Wang CQ, Li HY, Wang XJ (2014) A comparative study of the efficacy of through injured vertebra method and across the injured vertebra method in treatment of thoracolumbar spine fracture. J Bethune Med Sci 12(6):528-529

31. Ye C, Luo Z, Yu X, Liu H, Zhang B, Dai M et al (2017) Comparing the efficacy of short-segment pedicle screw instrumentation with and without intermediate screws for treating unstable thoracolumbar fractures. Med (United States) 96(34):e7893

32. Zhao QM, Gu XF, Yang HL, Liu ZT (2015) Surgical outcome of posterior fixation, including fractured vertebra, for thoracolumbar fractures. Neurosciences (Riyadh) 20(4):362-367

33. Luo J, Xu J (2014) Comparison on clinical efficacy by posterior fractured vertebral pedicle screws and posterior short segment pedicle instrumentation in the treatment of thoracolumbar fractures. IMHGN 20(5):656-659

34. Shu JC, Qiu ZJ, Shi KC, Wang LE, Pei FQ, Zhu Y (2015) Clinical investigation of short-segment pedicle fixation at fracture level in the treatment of thoracolumbar fractures. Chin J Bone Jt Inj 30(7):656-659

35. Zhu YR, Ye XJ, Yu JM, Jiang YQ, Wang HX, Fan CQ et al (2010) Posterior short-segment pedicle screw fixation at the injured level for thoracolumbar spine fractures. Chin J Traumatol 26(3):221-224

36. Guo J (2015) Pedicle screw fixation at the fracture level versus cross the fracture level for treatment of thoracolumbar fractures. Shenzhen J Integr Tradit Chin West Med 25(13):55-57

37. Xu JY, Liang ZH, He RL, Liao J, Jiang L (2015) Intermediate screws in short segment pedicular fixation with or without fracture vertebra for thoracic and lumbar fractures. China J Trauma Disabil Med 23(10):43-44

38. Huang W, Luo T (2013) Efficacy analysis of pedicle screw internal fixation of fractured vertebrae in the treatment of thoracolumbar fractures. Exp Ther Med 5(3):678-82

39. Chang R, Wang FA, Hao W (2014) Treatment of a thoracolumbar burst fracture with short segment pedicular screw fixation through the fractured vertebra. Orthop J China 22(8):683-686

40. Li C (2013) The clinical efficacy of short-segment fixation through the fracture level versus conventional method for spinal fracture. Henan J Surg 19(1):88-89
41. Wang JQ (2016) Comparison and analysis pedicle screw fixation through the fracture vertebra with across the fracture level for thoracolumbar fractures. Publ Med Forum 20(21):2909-2910

42. Ren HL, Wang JX, Jiang JM (2018) Is short same-segment fixation really better than short-segment posterior fixation in the treatment of thoracolumbar fractures? Spine (Phila Pa 1976) 43(21):1470-1478

43. Trungu S, Forcato S, Bruzzaniti P, Fraschetti F, Miscusi M, Cimatti $M$ et al (2019) Minimally invasive surgery for the treatment of traumatic monosegmental thoracolumbar burst fractures: clinical and radiologic outcomes of 144 patients with a 6-year follow-up comparing two groups with or without intermediate screw. Clin Spine Surg 32(4):E171-E176

44. McCormick JD, Werner BC, Shimer AL (2013) Patient-reported outcome measures in spine surgery. J Am Acad Orthop Surg 21:99-107

45. Mahar A, Kim C, Wedemeyer M, Mitsunaga L, Odell T, Johnson B et al (2007) Short-segment fixation of lumbar burst fractures using pedicle fixation at the level of the fracture. Spine (Phila Pa 1976) 32(14):1503-1507

46. Dobran M, Nasi D, Brunozzi D, di Somma L, Gladi M, Iacoangeli M et al (2016) Treatment of unstable thoracolumbar junction fractures: short-segment pedicle fixation with inclusion of the fracture level versus long-segment instrumentation. Acta Neurochir (Wien) 158(10):1883-1889

47. Li J, Liu L (2017) Comparison of short-segment versus longsegment fixation for the treatment of thoracolumbar burst fracture: a meta-analysis. Int J Clin Exp Med 10:1750-1762

48. Klezl Z, Majeed H, Bommireddy R, John J (2011) Early results after vertebral body stenting for fractures of the anterior column of the thoracolumbar spine. Injury 42(10):1038-1042

49. Pflugmacher R, Agarwal A, Kandziora F, Klostermann KC (2009) Balloon kyphoplasty combined with posterior instrumentation for the treatment of burst fractures of the Spine -1-Year results. J Orthop Trauma 23(2):126-131

50. Bornemann R, Jansen TR, Otten LA, Sander K, Wirtz DC, Pflugmacher R (2017) Comparison of radiofrequency kyphoplasty and balloon kyphoplasty in combination with posterior fixation for the treatment of vertebral fractures. J Back Musculoskelet Rehabil 30(3):591-596

51. Zhang C, Ouyang B, Li P, Wang L, Luo L, Zhao C et al (2017) A Retrospective Study of Thoracolumbar Fractures Treated with Fixation and Nonfusion Surgery of Intravertebral Bone Graft Assisted with Balloon Kyphoplasty. World Neurosurg 108:798-806

52. Zhang C, Liu Y (2018) Combined pedicle screw fixation at the fracture vertebrae versus conventional method for thoracolumbar fractures: A meta-analysis. Int J Surg 53:38-47

53. Li K, Zhang W, Liu D, Xu H, Geng W, Luo D et al (2016) Pedicle screw fixation combined with intermediate screw at the fracture level for treatment of thoracolumbar fractures: a meta-analysis. Medicine (Baltimore) 95(33): 4574

54. Tong MJ, Tang Q, Wang CG, Xiang GH, Chen Q, Xu HZ et al (2018) Efficacy of using intermediate screws in short-segment fixation for thoracolumbar fractures: a meta-analysis of randomized controlled trials. World Neurosurg 1(110):e271-e280

55. Tian F, Tu LY, Gu WF, Zhang EF, Wang ZB, Chu G, et al (2018) Percutaneous versus open pedicle screw instrumentation in treatment of thoracic and lumbar spine fractures: A systematic review and meta-analysis. Medicine (United States) 97

Publisher's Note Springer Nature remains neutral with regard to jurisdictional claims in published maps and institutional affiliations. 